\title{
In vitro Antibacterial Effect of Medicinal Plants against Multidrug Resistant Gram Negative Bacteria
}

\author{
Bishnu Thapa ${ }^{1}$, Anjana Singh ${ }^{1}$, Reshma Tuladhar ${ }^{{ }^{*}}$ \\ ${ }^{1}$ Central Department of Microbiology, Tribhuvan University, Kirtipur, Kathmandu, Nepal
}

"Corresponding author: Reshma Tuladhar, Central Department of Microbiology, Tribhuvan University, Kirtipur, Kathmandu, Nepal; E-mail: reshma.tuladhar@microbiotu.edu.np

\begin{abstract}
Objectives: The aim of this work was to determine the antibacterial activity of methanol extract of herbal plants against the multidrug resistant (MDR) Gram negative bacteria isolated from clinical samples.
\end{abstract}

Methods: Gram negative bacteria isolated from various clinical samples were processed for antibiotic susceptibility test by modified Kirby-Bauer disc diffusion method and MDR bacteria were selected. Methanol extracts of six different medicinal plants Acorus calamus (bojho), Ocimum sanctum (tulsi), Azadirachta indica (neem), Cinnamomum tamala (tejpatta), Aloe vera and Zanthoxylum alatum (timur), were tested for antibacterial activity against the selected MDR bacteria by agar well diffusion method.

Results: From clinical samples, 8 different MDR Gram negative bacteria isolated were Escherichia coli, Klebsiella pneumoniae, Klebsiella oxytoca, Citrobacter spp., Proteus mirabilis, Proteus vulgaris, Acinetobacter spp. and Pseudomonas spp. with E. coli dominated the number. Out of six medicinal plants extracts, Z. alatum, C. tamala and Ocimum sanctum were found to be effective with zones of inhibition ranging from 9-13 $\mathrm{mm}$. The medicinal plants with antibacterial activity can be an alternative source of medicine against MDR Gram negative bacteria.

Conclusion: Several herbal plants extracts exhibit antibacterial activity against MDR Gram negative bacteria. Antibacterial activity of plant extracts can vary with type of plant and extraction methods. Thus, for optimal benefit of plant extract, an appropriate extraction method and use of purified product is essential.

Key words: Multidrug resistant, medicinal plants, phytocompounds, antibacterial activity

\section{INTRODUCTION}

The efficacy of existing antibiotics is being threatened by the emergence of Multidrug resistant (MDR) bacteria (Dahiya and Purkayastha 2013). Treatment of infections due to MDR strains have clinically become intractable (Davies and Davies 2010) leading to prolonged hospitalizations, increased cost, and greater risk of morbidity and mortality (Dhital 2000). Resistance is a vexing problem especially for people with impaired immune systems, such as Acquired Immune Deficiency Syndrome, cancer patients and recipients of organ transplants (Russell 2002).

Date of Submission: November 2, 2018

Published Online: January 2019
Historically, pharmacological screening of compounds of natural or synthetic origin has been the source of innumerable therapeutic agents. Random screening of new biologically active molecules has been most productive in the area of antibiotics discovery (Ahmad et al. 2002). According to World Health Organization more than $80 \%$ of the world's populations rely on traditional medicine for their primary healthcare needs (WHO 1993). Use of herbal medicines in Asia represents a long history of human interactions with the environment and represents a rich source of antimicrobial agents and powerful drugs (Ahmad et al. 2002).

Date of Acceptance: December 9, 2018

DOI: https:// doi.org/10.3126/tujm.v5i0.22298 
Researchers are increasingly turning their attention towards the medicinal plants and it is estimated that, plant materials are present in, or have provided the models for $25-50 \%$ western drugs (Cragetal. 2013). Many commercially available drugs used in modern medicine were initially used in crude forms in traditional or folk healing practices, or for other purposes that suggested potential biological activity (Anthony and Livermore 2015). Plant derived medicines are relatively safer than synthetic alternatives and offer affordable therapeutic benefits (Hammer et al. 1990).

Plants produce enormous variety of small molecules classified as phytoalexins which have been assumed to play important role in the defenses mechanisms of the plants (Rathanyaka and Obreshkova 2013). Phytoalexins are low molecular weight, anti-microbial compounds that are synthesized and accumulated in plants after exposure to microorganisms or abiotic agents (Khan et al. 2010). Phytoalexins structural spaces contain terpenoids, glycosteroids, flavonoids and polyphenols and these biologically active compounds are supposed to exhibit antimicrobial properties (Azwaninda 2016). Medicinal and aromatic plants have potential for contributing to the local economy, subsistence health needs, and improved natural resource management.

Thus, it was deemed important to consider for investigation of antimicrobial activity of herbal plants against MDR Gram negative isolates from the clinical samples. In this study the medicinal plants were selected based on their common uses in Nepali traditional systems. In view of vast potential of plants as sources for antimicrobial drugs with reference to antibacterial agents, six common floras, Acorus calamus (bojho), Ocimum sanctum (tulsi), Azadirachta indica (neem), Cinnamomum tamala (tejpatta), Aloe vera and Zanthoxylum alatum (timur) were selected to evaluate the antibacterial activity.

\section{MATERIALS AND METHODS}

Gram negative bacteria isolated from different clinical samples (urine, pus and sputum) were identified by standard microbiological techniques which included colonial morphology, Gram staining and biochemical tests. Antibiotic susceptibility tests of the identified bacteria were performed by modified Kirby-Bauer disk diffusion method in Mueller Hinton agar (MHA) according to CLSI guideline (2014). MDR bacteria were categorized as per the definition given by Magiorakos et al. (2012).

The medicinal plants Acorus calamus (bojho), Ocimum sanctum (tulsi), Azadirachta indica (neem), Cinnamomum tamala (tejpatta), Aloe vera and Zanthoxylum alatum (timur) selected for this research were collected from Jhapa and Kathmandu. Identification of these plants and processing for extraction was done in Department of plant resources, Thapathali, Kathmandu.

Root of A. calamus, leaves of O. sanctum, A. indica, C. tamala and Aloe vera, and seeds of Z. alatum were washed thoroughly. Roots and leaves were cut into tiny pieces $(3-5 \mathrm{~cm})$ with the help of sterile knife. They were spread and left to air dry for 10-12 days with periodical turning. Fine powders of dried samples were obtained by grinding in an electrical grinder. Extraction from approximately 70-90 gm of powdered form was carried out by Soxhlet extraction method using methanol as solvent. Rotatory evaporator was used under negative pressure at water bath below $55^{\circ} \mathrm{C}$ to remove the solvent. The crude extract obtained in round bottom flask was further assayed for antibacterial activity.

Agar well diffusion method was used for in-vitro antibacterial activity of the extracts against the MDR Gram negative bacterial isolates. The fresh inoculums of MDR bacterial isolates compared with McFarland standard were spread uniformly on the surface of sterile MHA plates. Six wells were prepared in each plate with the help of $8 \mathrm{~mm}$ diameter cork borer. Then, $50 \mu \mathrm{l}$ of methanol extract $(100 \mu \mathrm{g} / \mathrm{ml})$ from the selected plants were loaded in each well with the help of micropipette (Redfern et al. 2014). The plates were left for diffusion of extract for 15 minutes and was incubated overnight at $37^{\circ} \mathrm{C}$ and observed for the zone of inhibition.

\section{RESULTS}

Out of different clinical samples processed, $33.5 \%$ showed positive for bacterial growth among which $40.9 \%$ were Gram negative isolates. Eight different MDR Gram negative bacteria isolated were Escherichia coli, Klebsiella pneumoniae, Klebsiella oxytoca, Citrobacter spp., Proteus mirabilis, Proteus vulgaris, Acinetobacter spp. and Pseudomonas spp. with the highest number of E. coli (Figure 1). Of the total E. coli isolated 32.1\% were MDR. Similarly, $17.9 \%$ K. oxytoca, $14.1 \%$ of K. pneumoniae, $3.8 \%$ of each of $P$. vulgaris and P. mirabilis, 2.6\% Acinetobacter spp., and $1.3 \%$ each of Citrobacter spp. and Pseudomonas spp. were isolated. 


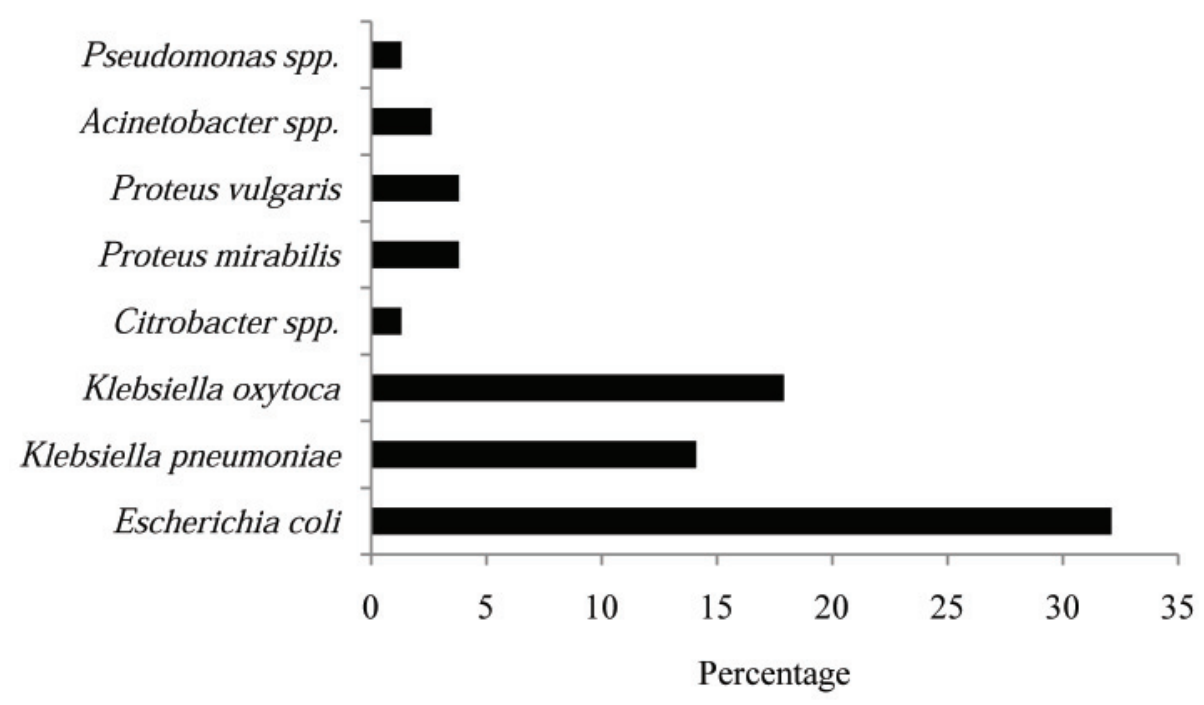

Figure 1: Gram negative MDR bacteria prevalent in clinical specimens

Antimicrobial activity of crude extracts of medicinal plants, A. calamus, O. sanctum, A. indica, C. tamala, Aloe vera, and $Z$. alatum when tested against the isolated Gram negative MDR bacteria, some of them showed activity against few bacteria. Table 1 shows the number of E. coli isolates inhibited by the plant extracts. Out of 24 isolates tested for antibacterial activity, 5 were inhibited by Z. alatum and 4 by $O$. sanctum but other plant extracts did not show any activity.

Table 1: Number of Antibacterial effect of methanol herbal extracts against MDR E. coli (n=24)

\begin{tabular}{llcc}
\hline S.N. & Plant extract & Active & Inactive \\
\hline 1 & A. calamus & 0 & 24 \\
2 & A. indica & 0 & 24 \\
3 & A. vera & 0 & 24 \\
4 & C. tamala & 0 & 24 \\
5 & Z. alatum & 5 & 19 \\
6 & O. sanctum & 4 & 20 \\
\hline
\end{tabular}

Among 12 K. pneumoniae tested, only 2 were inhibited by $C$. tamala and none were inhibited by remaining plant extracts (Table 2). Similarly, each of 2 isolates of K. oxytoca were inhibited by Z. alatum and O. sanctum, and one isolate was inhibited by A. vera and C. tamala each (Table 3).

None of the isolate of $P$. vulgaris, P. mirabilis, Acinetobacter spp., Citrobacter spp. and Pseudomonas spp. was inhibited by the plant extracts.

Table 2: Antibacterial effect of methanol herbal extracts against MDR K. pneumoniae (n=12)

\begin{tabular}{llcc}
\hline S.N. & Plant extract & Active & Inactive \\
\hline 1 & A. calamus & 0 & 12 \\
2 & A. indica & 0 & 12 \\
3 & A. vera & 0 & 12 \\
4 & C. tamala & 2 & 10 \\
5 & Z. alatum & 0 & 12 \\
6 & O. sanctum & 0 & 12 \\
\hline
\end{tabular}


Table 3: Antibacterial effect against MDR K. oxytoca $(\mathbf{n}=\mathbf{1 4})$

\begin{tabular}{llcc}
\hline S.N. & Plant extract & Active & Inactive \\
\hline 1 & A. calamus & 0 & 14 \\
2 & A. indica & 0 & 14 \\
3 & A. vera & 1 & 13 \\
4 & C. tamala & 1 & 13 \\
5 & Z. alatum & 2 & 12 \\
6 & O. sanctum & 2 & 12 \\
\hline
\end{tabular}

Among the extracts, Z. alatum was found to be effective with $11.7 \%(n=7)$ showing active effect against MDR Gram negative bacteria followed by $O$. sanctum and $C$. tamala with $10 \%(\mathrm{n}=6)$ and $5.1 \%(\mathrm{n}=5)$. A. calamus and A. indica were found to be most ineffective medicinal plants (Figure 2).

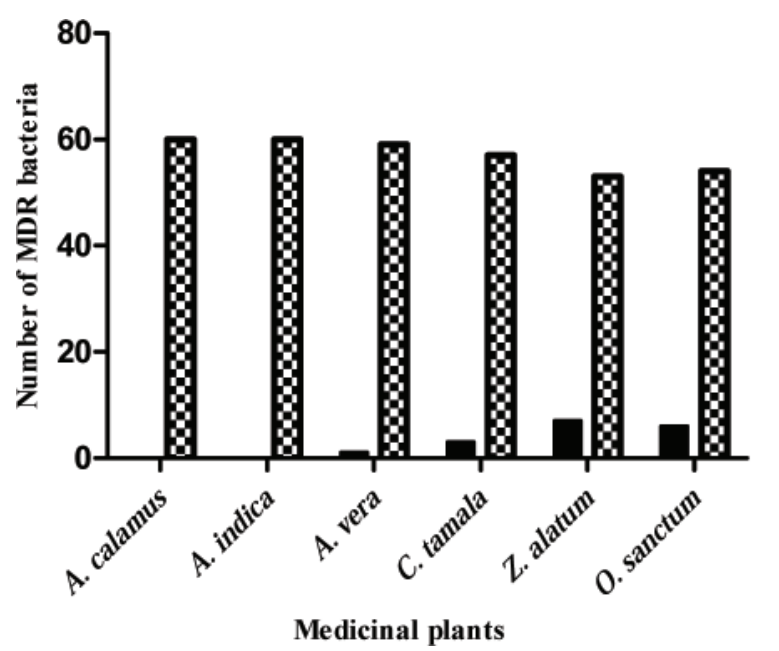

Figure 2: Comparison of antibacterial effect of medicinal plants against the MDR Gram negative bacteria

\section{DISCUSSION}

Diverse plants possess a variety of bioactive compounds at different concentration. Bioactive compounds derived from plants extracts can differ in their chemical composition and polarities. Thus, it is imperative to select solvent wisely to dissolve most of the compounds from the plants extract (Alekshun and Vijayalaxmi 2013). Methanol was used for the extraction of bioactive compounds from the selected plants in this research since it has polarity index of 5.1, which makes it an efficient solvent. Besides it is relatively cheap, free of regulation and gets evaporated easily (Crag et al. 2013). We selected the six medicinal plants in view of the fact that they are easily available and most commonly used by people in Nepal.

From the antibacterial assay, the selected plants exhibited zone of inhibition within the range of 10-12 mm. In a similar study by Ahmad et al. (2002), zone of inhibition from 11-14 mm against MDR Gram negative isolates was observed. While Rastogi et al. (2015) concluded that the inhibition zone was found within the range of $12-26 \mathrm{~mm}$ from different medicinal plants (Cassia fistula, Holarrhena antidysenterica, Terminalia alata, T. arjuna and Paederia foetida). Variation in zone of inhibition by the extracts against the MDR Gram negative isolates might be due to the differences in the type of solvents used for the extraction which is responsible for dissolving bioactive compounds and also based on the selection of plants for bioactive compounds.

Medicinal plants contain complex phenol compounds and the mechanism of action of each phenolic compound against various bacteria is also very complicated. Therefore, it is necessary to investigate further with purified extract instead of crude extract to understand the relationship between the antibacterial activity and 
chemical structure of each phenolic compound in the extracts (Burt 2005).

A. calamus was found to be inactive against MDR Gram negative strains in the present study. However the rhizome of A. calamus (Chhatopadhyay et al. 2010) exhibited $16 \mathrm{~mm}$ zone of inhibition, which did not support the present finding. The possible reason for this might be different extraction methods adopted by other researcher for the extract preparation resulting in antibacterial effect.

Similarly, A. indica was found to be inactive against MDR Gram negative strains in the present study. However, a study from India revealed that $A$ indica successfully exhibited zone of inhibition at the range of $12-19 \mathrm{~mm}$ against MDR Gram negative pathogens (Monali et al. 2015). Neem has been known to possess antibacterial activity. But the reason for not observing any activity by this compound might be due to possible damage of the compound during extraction or insufficient amount of active compound in crude extract.

The methanol extracts of Z. alatum was the most effective compound to exhibit antibacterial effect against MDR Gram negative isolates with $11.7 \%$ active effect which was similar to a study conducted by Hanberger et al. (2003). The methanolic stem extract of Z. alatum indicated moderate inhibition of E. coli, K. pneumoniae $(11.0 \pm 1.0 \mathrm{~mm} ; 11.0 \pm 1.0 \mathrm{~mm})$ while leaf extracts showed the greatest effect on E. coli, K. pneumoniae. (14.0 \pm 1.0 $\mathrm{mm}$ ) at $100 \mathrm{mg} / \mathrm{ml}$ (Guleria et al. 2014). The bioactive constituents of the Z. alatum corresponding to Za1 and Za2 were identified as -fenchol and linalool, which might be the cause of antibacterial property (Guleria et al. 2014). Several workers have reported that the phenolic compounds present in Z. alatum acts as reducing agent and owe to the antibacterial activity against MDR pathogens (Jain 2016) while others revealed that bioactive compounds like 2-decanone, 4-terpineol and linalol can be possible factor for antibacterial activity in Z. alatum (Ebrahimabadi et al. 2010).

C. tamala, on the other hand, exhibited antibacterial effect with 5\% activity against the MDR Gram negative isolates. Studies suggested that the antibacterial activity of cinnamon was probably due to their major component, cinnamaldehyde, a natural antioxidant (Monali et al. 2015). Cinnamaldehyde was found to completely inhibit both sensitive and resistant strain of Helicobacter pylori (Joshi and Edington 1990). Leaves of O. sanctum exhibited antibacterial effect with $10 \%$ activity which is in consistent with result from a study conducted by Jain et al. (2012), in which the leaves inhibited growth of E. coli and S. aureus. However the result obtained was different with Ahmad et al. (2002) where the leaves of $O$ sanctum did not show any zone of inhibition against MDR E. coli.

All the extracts were found to be inactive against the MDR P. vulgaris, P.mirabilis, Acinetobacter spp., Citrobacter spp. and Pseudomonas spp. Similarly, a study from India by Jacoby et al. (2012), revealed that among the Gram negative tested for the antibacterial activity, only two strains of $P$. aeruginosa (ATCC 2642) were the least sensitive to the oil extracts (MIC value $>100 \mathrm{mg}$ / $\mathrm{ml})$.

The differences in the activities of extracts of various plants may be due to varying degrees of solubility of the active constituents in methanol. It has been documented that different solvents have different solubility capacities for different phytoconstituents (Hammer et al.1990). Besides, differences were observed in antibacterial activities of the different extracts. These differences could be due to the dissimilar secondary metabolites of plants (Djeussi et al. 2013).

Plant based antimicrobials have enormous therapeutic potential as they can serve the purpose with lesser side effects that are often associated with synthetic antimicrobials (Vieira and Simon 1999).

\section{CONCLUSION}

Three of the selected medicinal plants $(O$. sanctum, Z. alatum and C. tamala) were successful in exhibiting antibacterial effect against common MDR Gram negative isolates. In response to the propagation of bacterial resistant to many antibiotics, also called MDR bacteria, the discovery of new and more efficient antibacterial agents is essential.

\section{ACKNOWLEDGEMENTS}

We are grateful to all the staff of Sahid Memorial Hospital, Kalanki, Kathmandu, Nepal for their assistance. We are also thankful to Department of Plant Resources, Thapathali, Kathmandu for helping in plant extraction process.

\section{CONFLICT OF INTEREST}

The authors declare no conflict of interest.

\section{REFERENCES}

Ahmad I, Mehmood Z and Mohammad F (2002). 
Screening of some Indian medicinal plants for their antimicrobial properties. J Ethno Pharmacol 62: 183-193.

Alekshun K and Vijayalakshmi G (2013). Improved shelf life of protein-rich tofu using Ocimum sanctum (tulsi) extracts to benefit Indian rural population. J Food Sci 72: 300-305.

Anthony CM and Livermore DM (2015). Resistance to antimicrobial drugs: a worldwide calamity. Ann Intern Med 18: 557-561.

Azwaninda NN (2016). A review on the extraction methods use in medicinal plants, principle, strength and limitation. Med Aromat Plants 4: 196.

BurtS (2004). Essential oils: their antibacterial properties and potential applications in foods $-\mathrm{a}$

review. Int J Food Microbiol 94: 223-253.

Chhatopadhyay M, Ali SR and Aboud S (2010). Antimicrobial activities of aqueous and methanolic extracts from Acorus calamus used in the treatment of wound infection isolates. Int $J$ Infect 2: 18-25.

Clinical and Laboratory Standards Institute (2014). Performance standards for antimicrobial susceptibility testing; twenty-fourth informational supplement, M100-S24. Clinical and Laboratory Standards Institute, Wayne, PA pp 121-148.

Crag GM, Newman DJ and Sander KM (2013). Natural products in drug discovery and development. J Nat Prod 60: 52-60.

Dahiya P and Purkayastha S (2013). Phytochemical screening and antimicrobial activity of some medicinal plants against multi-drug resistant bacteria from clinical isolates. Indian J Pharm Sci 74: $443-450$

Davies J and Davies D (2010). Origins and evolution of antibiotic resistance. Microbiol Mol Biol Rev 74: 417-433.

Dhital S (2000). Determination of antibiotic resistant Gram negative urinary pathogen in pediatric patients at Kanti Children's Hospital. A dissertation submitted to Central Department of Microbiology, Tribhuvan University, Kathmandu, Nepal pp 27-32.

Djeussi DE, Noumedem JA, Seukep JA, Fankam AG,
Voukeng IK and Tankeo SB (2013). Antibacterial activities of selected edible plants extract against multidrug-resistant Gram negative and Gram positive bacteria. BMC Complement Altern Med 13: 164.

Ebrahimabadi AH, Ebrahimabadi EH, Bidgoli Z, Kashi FJ, Mazoochi A and Batooli H (2010). Composition and antioxidant and antimicrobial activity of the essential oil and extracts of Dioscorea hispida from Iran. J Rural Trop Health 19: 452-458.

Guleria S, Tiku AK, Koul A, Gupta S, Singh G and Razdan VK (2014). Antioxidant and antimicrobial properties of the essential oil and extracts of Zanthoxylum alatum grown in North-Western Himalaya. J Med Plants Res 6: 971-976.

Hammer KA, Carson CF and Riley TV (1990). Antimicrobial activity of essential oils and other plant extracts. J App Microbiol 86: 985-990.

Hanberger HL, Didier M and Antoine T (2003). Antimicrobial resistance among uropathogens that cause community acquired UTI in Bangui, Central African Republic. J Antimicrob Chemother 51:192-194.

Jacoby B, Ebadi A, Aghdam BM and Hassanzade Z (2012). Antibacterial activities of lemon grass methanol extract and essence in pathogenic bacteria. American-Eurasian J Agri Env Sci 12: 1042-1046.

Jain R, Katare N and Kumar V (2012). In vitro antibacterial potential of different extracts of Ocimum spp. J Nat Sci Res 2: 84-90.

Jain N, Srivastava SK, Aggarwal KK, Ramesh S, and Kumar S (2016). Essential oil composition of Zanthoxylum alatum seeds from northern India. J Med Plants Res 16: 408-410.

Joshi AR and Edington JM (1990). The use of medicinal plants by two village communities in the central development region of Nepal. Economic Botany 44: 71-83.

Khan R, Islam B, Akram M, Shakil S, Ahmad A and Ali SM (2010). Antimicrobial activity of five herbal extracts against multidrug resistant strains of bacteria and fungus of clinical origin. Pak J Bot 14: 586-597.

Magiorakos M, Fazilah A, Norzials MH and Karim AA 
(2012). Antimicrobial activity and mechanical properties of partially hydrolyzed sago starchalginate edible film containing lemon grass oil. J Food Sci 72: 324-330.

Monali P, Mishra R, Shasank S, Goutam G, Debajyoti Das and Rabindra N (2015). In vitro antibacterial activity of crude extracts of nine selected medicinal plants against UTI causing MDR bacteria. J King S U 4: 36-44.

Rastogi RP and Mehrotra BN (2015). Glossary of Indian medicinal plants. Indian J Med Microbiol 9: 102118.

Rathnayaka G and Obreshkova D (2013). Comparitive studies on the activity of basil-an essential oil from Ocimum basilicum L.-against multidrug resistant clinical isolates of the genera Staphylococcus, Enterococcus and Pseudomonas by using different test methods. J Microbiol Methods 54: 105-110.
Redfern J, Kinninmonth M, Burdass D and Verran J (2014). Using soxhlet ethanol extraction to produce and test plant material (essential oils) for their antimicrobial properties. J App Microbiol 1: 45-46.

Russell AD (2002). Antibiotic and biocide resistance in bacteria: Introduction. J App Microbiol 92: 15-35.

Sasidharan S, Chen Y, Saravanan D, Sundram KM and Latha L (2010). Extraction, isolation and characterization of bioactive compounds from plant extracts. Indian J Pharma Sci 3:1-10.

Vieira RF andSimonJE (1999). Chemicalcharacterization of basil (Ocimum spp.) found in the markets and used in traditional medicine in Brazil. J Sociedade Botanica de Sao Paulo 54: 207-216.

WHO (1993). Summary of WHO guidelines for the assessment of herbal medicines. Herbal Gram 28: 13-14. 